\title{
Selection on floral traits through male fertility in a natural plant population
}

\author{
Mark van Kleunen · Jaroslaw Burczyk
}

\begin{abstract}
Most studies on selection in plants estimate female fitness components and neglect male mating success, although the latter might also be fundamental to understand adaptive evolution. Information from molecular genetic markers can be used to assess determinants of male mating success through parentage analyses. We estimated paternal selection gradients on floral traits in a large natural population of the herb Mimulus guttatus using a paternity probability model and maximum likelihood methods. This analysis revealed more significant selection gradients than a previous analysis based on regression of estimated male fertilities on floral traits. There were differences between results of univariate and multivariate analyses most likely due to the underlying covariance structure of the traits. Multivariate analysis, which corrects for the covariance structure of the traits, indicated that male mating success declined with distance from and depended on the direction to the mother plants. Moreover, there was directional selection for plants with fewer open flowers which have smaller corollas, a smaller anther stigma separation, more red dots on the corolla and a larger fluctuating asymmetry therein. For most of these traits, however, there was also stabilizing selection indicating that there are intermediate optima for these traits. The large number of significant selection gradients in this study shows that even in relatively large natural populations where not all males can be sampled, it is possible to detect significant paternal selection gradients, and that such studies can give us valuable information required to better understand adaptive plant evolution.
\end{abstract}

M. van Kleunen ( $\square)$

Centre for Invasion Biology, School of Biological and Conservation Sciences, University of KwaZulu Natal, P. Bag X01, Scottsville, Pietermaritzburg 3209, South Africa e mail: vankleunen@ukzn.ac.za

J. Burczyk

Department of Genetics, Institute of Biology and Environmental Protection, University of Bydgoszcz, ul. Chodkiewicza 30, 85064 Bydgoszcz, Poland

e mail: burczyk@ukw.edu.pl 
Keywords Isozymes $\cdot$ Natural selection $\cdot$ Mating system $\cdot$ Paternity $\cdot$ Pollen dispersal $\cdot$ Reproduction

\section{Introduction}

A trait can only change through adaptive evolution when it affects fitness. This is usually tested with selection gradient analysis in which fitness is regressed on trait values of interest (Lande and Arnold 1983). In most of these studies on plants, seed production or plant size have been used as estimates of fitness (e.g., Dudley 1996; van Kleunen and Fischer 2001), thereby restricting these studies to effects of traits on female fitness components. Male fertility, however, contributes half of the genes to the next generation, and is thus equally important as female fertility to overall fitness. Male and female fertility of a plant, however, are not necessarily correlated (Devlin and Ellstrand 1990), and as a consequence plant traits, especially floral traits involved in attraction of pollinators, may be under different selection through male and female fitness components (Schoen and Clegg 1985; Stanton et al. 1986).

In contrast to female fertility, male fertility is much more difficult to estimate. The removal of pollen grains from anthers and their deposition on stigmas have frequently been used as estimates of male mating success (e.g., Campbell 1989; Young and Stanton 1990; O'Connell and Johnston 1998). However, these estimates do not necessarily correlate with the actual male fertility for three reasons. First, pollen removed from anthers is not necessarily deposited on receptive stigmas of other conspecific plants. This is particularly true for plants in which pollen is also a food reward for pollinators. Second, even when a pollen grain is deposited on a receptive stigma, the pollen gamete does not necessarily fertilize the ovules as a consequence of self-incompatibility mechanisms (De Nettancourt 1977) or pollen competition (Mulcahy 1979; Waser et al. 1987). Third, even when a pollen gamete fertilizes an ovule, there may be selective abortion of seeds (Marshall and Ellstrand 1988) and fruits (Stephenson 1981), and selective germination. This implies that for many plants, estimation of individual male mating success requires determination of paternity of the offspring (Snow and Lewis 1993).

Molecular genetic markers such as allozymes can be used to assess paternity of offspring and subsequently male mating success (e.g., Broyles and Wyatt 1990; Adams and Birkes 1991; Smouse et al. 1999). Although several approaches to estimate selection through male fertility have been proposed, there have been only few studies that applied them. The simplest approach is to first estimate individual male mating success from molecular genetic data, and then, like in classical selection gradient analysis (Lande and Arnold 1983), to regress these values on the traits of interest (e.g., Schoen and Stewart 1986; Devlin and Ellstrand 1990; Conner et al. 1996; van Kleunen and Ritland 2004). The power of this method, however, is relatively low because assumptions underlying regression are violated (Smouse et al. 1999) as a consequence of inflated error variance of male fertility estimated from molecular data (Devlin et al. 1988). This is especially true when genetic discrimination is low (Roeder et al. 1989). A potentially more powerful approach is estimation of paternal selection gradients directly from the molecular genetic data and the trait values by using probability models that account for the genetic composition of offspring in progeny arrays, and estimating the selection coefficients 
using maximum-likelihood methods (Adams and Birkes 1991; Burczyk et al. 1996, 2002; Smouse et al. 1999; Morgan and Conner 2001).

In a previous study, van Kleunen and Ritland (2004) tested for selection on eight floral traits in a natural population of Mimulus guttatus by simple regression of male fertility estimated from allozyme data on floral traits. Although floral characteristics involved in pollinator attraction such as shape, size and reward are often supposed to be under strong selection, van Kleunen and Ritland (2004) only found a significant negative paternal selection coefficient for anther stigma separation. This suggests that either selection on floral traits through male fertility is limited or that the power to detect selection through male fertility was too low in that study. Therefore, we reanalysed this data-set with a probability model and maximum-likelihood methods.

Most studies on natural selection only test for directional selection on traits even though it is generally assumed that most traits have intermediate optima (Stearns and Hoekstra 2000). Therefore, we also tested for stabilizing and disruptive selection on floral traits by including their quadratic components in the selection gradient analyses. Further, because male mating success may be strongly affected by the spatial location of plants in the population which might obscure the effects of plant traits on male mating success (Devlin and Ellstrand 1990), we corrected for this by including distance and direction to other plants in the model (Burczyk et al. 1996).

\section{Materials and methods}

\section{Study species}

The yellow monkey flower, Mimulus guttatus FISCH. ex DC. (Phrymaceae), is an annual or perennial herb that is native to western North America and has been introduced into eastern North America, New Zealand and Europe. The species occurs in moist habitats such as small streams, wet meadows, and on wet bluffs along the sea.

Shoots of $M$. guttatus consist of $0.11 \mathrm{~m}$ high stems which bear two opposite $15 \mathrm{~cm}$ long egg- or hearth-shaped leaves at each node. Side branches and single flowers are produced from meristems in the axils of the leaves. Stems may layer and root at the nodes resulting in vegetative reproduction. The funnel-shaped zygomorphic yellow flowers are $14 \mathrm{~cm}$ long and have conspicuous red dots at the mouth and inside the funnel. It has been suggested that the red dots might direct pollinators to the two pairs of anthers in the flower (Robertson et al. 1999). The self-compatible flowers produce no or very small amounts of nectar (Robertson et al. 1999), and are mainly pollinated by bees and bumblebees foraging for pollen (Kiang 1972).

\section{Data-set}

The data-set is described in van Kleunen and Ritland (2004). In short, between May 2124 2002, we marked 287 shoots in a natural population located on a wet bluff along the ocean in Lighthouse Park, $10 \mathrm{~km}$ north-west of Vancouver, British Columbia. The population consisted of ca. 3,000 flowering shoots patchily distributed within a ca. $100 \mathrm{~m}^{2}$ area (Fig. 1). Because most plants in the population 


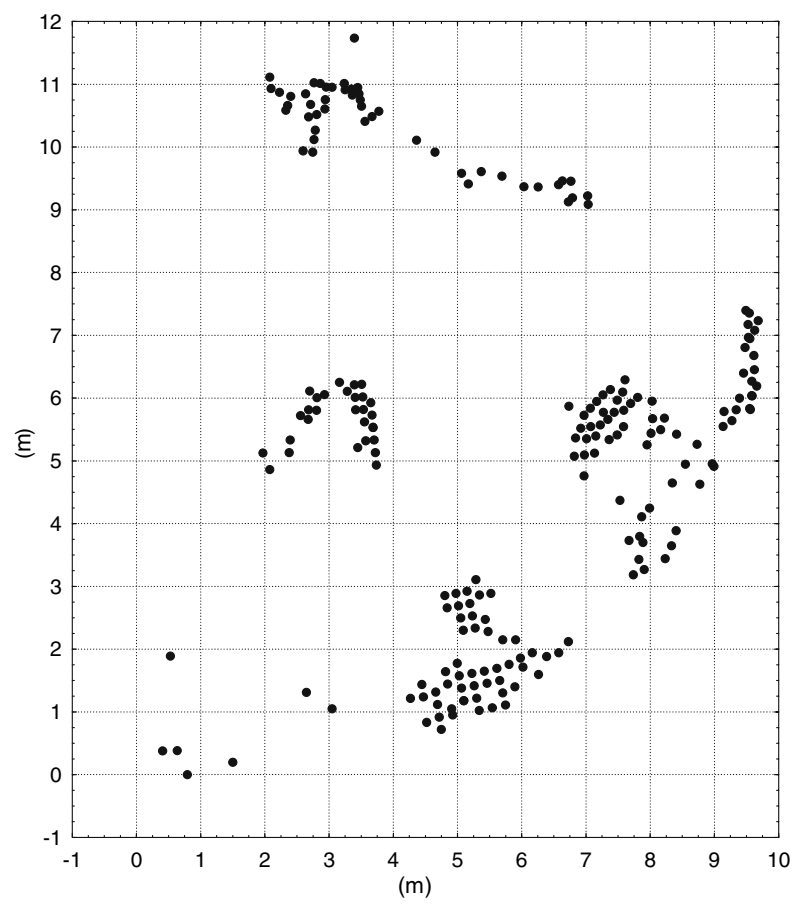

Fig. 1 Distribution of sampled shoots in the plot representing the patches of Mimulus guttatus

were perennial with vegetatively reproduced shoots, the actual population size was most likely much smaller than 3,000 clones. To sample as many different clones as possible, the distance between marked shoots was at least $30 \mathrm{~cm}$. We determined the position of each marked shoot in the population by measuring its distance to and direction from a common reference point. We counted the number of open flowers per shoot, and collected the most recently opened flower. As measures of flower size and shape, we measured the width and length of the corolla, and calculated their ratio. We measured the length of the pistil and the longest pair of stamens, and calculated the anther stigma separation as their difference. We measured the length of the anther sac on the left longest stamen, which correlates positively with pollen production (Ritland and Ritland 1989). We determined the proportion of non-viable pollen under a light microscope after staining with lactophenol analine blue. As measure of female reproductive effort we measured the length of the ovary, which correlates positively with the number of ovules (Ritland and Ritland 1989). We counted the number of red dots on both the left and right half of the flower. As a measure of developmental instability, we calculated fluctuating asymmetry (FA) in the number of red dots as the absolute difference between the ln-transformed number of red dots on the left and right half of each flower. The number of open flowers and proportion of non-viable pollen were $\log 10$-transformed prior to analyses.

In the period from mid-June to August 2002, we revisited the population every week and collected from each measured plant one full seed capsule as close as 
possible to the position of the measured flower. On August 28 2002, we sowed for each maternal plant 510 seeds into 10 cells of $5 \times 6 \times 6 \mathrm{~cm}$ of multi-top trays filled with commercial potting compost in a greenhouse with additional lighting to extend the daily light period to $16 \mathrm{~h}$. During the next month, we thinned seedlings to one per cell. When the plants were flowering, we collected corollas from 1,642 offspring plants representing 212 mother plants for allozyme analyses using starch-gel electrophoresis (van Kleunen and Ritland 2004). We scored eight polymorphic loci: aconotase (allele frequencies: 0.776, 0.224), alcohol dehydrogenase $(0.503,0.497)$, isocitrate dehydrogenase $(0.961,0.039)$, malic enzyme $(0.720,0.265,0.016)$, phosphoglucoisomerase $(0.948,0.052)$, phosphoglucomutase $(0.905,0.095)$ and 6-phophogluconic dehydrogenase ( 2 loci; $0.954,0.046$, and $0.575,0.425$, respectively). The cumulative exclusion probability of the marker set was 0.610 .

The paternity model

The paternity model that we used states that an offspring of a particular mother plant may be the result of self-fertilization with probability $s$, and cross-fertilization with probability $\left(\begin{array}{ll}1 & s\end{array}\right)$. The probability of observing a specific multi-locus diploid genotype $g_{i j}$ in the offspring of the $j$-th mother is

$$
P\left(g_{i j} \mid M_{j}\right)=s P\left(g_{i j} \mid M_{j}, M_{j}\right)+(1-s) \sum_{k} \phi_{j k} P\left(g_{i j} \mid M_{j}, F_{j k}\right) .
$$

Here the genetic segregation probabilities $P\left(g_{i j} \mid M_{j}, M_{j}\right)$, and $P\left(g_{i j} \mid M_{j}, F_{j k}\right)$ are the probabilities that an offspring has genotype $g_{i j}$ when a mother plant of genotype $M_{j}$ is, respectively, self pollinated and cross pollinated by a male with genotype $F_{j k}$. The parameter $\phi_{j k}$ (male fertility) is the phenotypic probability that the sampled $k$-th male has fathered offspring of the $j$-th mother in the population (Smouse et al. 1999; Burczyk et al. 2002).

Individual male fertilities are directly related to factors influencing them by using the following exponential equation:

$$
\phi_{j k}=\frac{\exp \left(u_{j k}\right)}{\sum_{h 1}^{r} \exp \left(u_{j h}\right)},
$$

where $u_{j k}$ is a function of one or more factors that might affect the mating success of the $k$-th male in the neighbourhood of the $j$-th mother (Burczyk et al. 2002). The denominator in Eq. 2 is the sum of exp $\left(u_{j h}\right)$ over all sampled males $(r)$ in the neighbourhood of the $j$-th mother so that

$$
\sum_{h 1}^{r} \phi_{j h}=1 .
$$

Selection gradient coefficients can reflect linear (i.e., directional) or quadratic (i.e., stabilizing or disruptive) selection. Therefore, we used the following equation (Morgan and Conner 2001; Wright and Meagher 2004): 


$$
u_{j k}=\sum_{f=1}^{z}\left(\lambda_{f} x_{j k f}+\gamma_{f} x_{j k f}^{2}\right)
$$

Here, $\lambda_{f}$ and $\gamma_{f}$ are selection gradient coefficients describing, respectively, linear and quadratic selection on the $f$-th factor out of $z$, and $x_{j k f}$ is the standardized value of the $f$-th trait (factor) observed in the $k$-th male within the population of the $j$-th mother.

To test and control for spatial position of plants on male mating success, we included distance from and direction relative to mother plants in all investigated mating models (Burczyk et al. 1996). Therefore, the function $u_{j k}$ (Eq. 3) used to estimate individual male mating success $\phi_{j k}$ (Eq. 2) was defined as

$$
u_{j k}=\beta d_{j k}+\delta \cos \left(\alpha_{j k}-\alpha_{0}\right)+\sum_{f=1}^{z}\left(\lambda_{f} x_{j k f}+\gamma_{f} x_{j k f}^{2}\right) .
$$

Here $d_{j k}$ is the distance of the $k$-th male from the $j$-th mother plant and $\cos \left(\alpha_{j k} \alpha_{0}\right)$ is the cosine of the angle between the presumed prevailing direction of effective pollen dispersal $\alpha_{0}$, which is to be estimated, and the location of the $k$-th male (Burczyk et al. 1996). Specifically, $\beta$ and $\delta$ are coefficients describing the effect of distance and directionality upon the male mating success that are to be estimated.

The likelihood of the entire data set is the product over all offspring:

$$
L(s, \theta)=\prod_{j}^{N} L_{j}=\prod_{j}^{N} \prod_{1}^{n_{j}} P\left(g_{i j} \mid M_{j}\right)
$$

The estimates of $s$, and the vector $\theta$ consisting of a set of gradient coefficients that maximize $L(s, \theta)$ are obtained using maximum-likelihood methods based on numerical procedures (Burczyk et al. 1996; Burczyk et al. 2002). The estimates of gradient coefficients are also used further to estimate effective number of males and the distance of effective pollen dispersal (Burczyk et al. 2002).

Given estimates of the gradient coefficients in the best-fitting model, fertilities of individual males within a local population can be derived (Eq. 2). Then, the effective number of males siring the offspring of $j$-th mother can be estimated based on individual male fertilities as $N e_{j}=1 / \Sigma \phi_{j k}^{2}$ (Burczyk et al. 2002). The effective number of males is the equivalent number of male parents in an idealized situation where all males in the neighbourhood have equal fertilities (Crow and Kimura 1970). The estimates are averaged across all females and because they are based on individual male fertilities, they are independent of the number of progeny samples.

\section{Analyses}

The paternal probability model requires that the genotypes of the mother plants, their offspring and potential fathers are known. Because we only did allozyme analyses on the offspring, we obtained the mother genotypes from their progeny arrays by using the computer program MLTR (available at http://www.genetics. forestry.ubc.ca/ritland/programs.html, last visited 9 May 2006; Ritland 2002). Subsequently, since we attempted to sample within the population as many different 
clones as possible (see Data-set section) we used the mother genotypes also as genotypes of potential fathers. For the analyses of paternal selection gradients, we used the computer program NEIGHBOR v2.1 (Burczyk et al. 2002), which can be requested from the second author. This program has specifically been upgraded for this study to analyse up to 20 selection gradient coefficients simultaneously. It should be noted that the NEIGHBOR program allows for estimating the proportion $(m)$ of offspring resulting from pollen immigration (gene flow) from outside of the sampled plot. We attempted to estimate $m$ from the data set, however, the estimates were very variable $\left(\begin{array}{ll}0.10 & 0.50\end{array}\right)$ depending on the complexity of the model and loaded with large variances, probably due to low exclusion power of the markers and relatively large number of potential local fathers. Moreover, the iterative estimation procedures (see below) could not converge for the full multivariate model. Therefore, all analyses were performed assuming no immigration. Eight offspring (out of 1,642) for which there were no compatible fathers within the local population were excluded from the analyses.

We started the analyses by estimating gradient coefficients for univariate models. Such models included only $s, \beta, \delta, \alpha_{0}$ and either a single linear selection gradient coefficient or both a linear and quadratic one for a given factor. Then, selection gradient coefficients were estimated based on multivariate models, including a set of linear and quadratic terms for a number of factors. The reason for using multivariate models is that several traits investigated in this study are correlated in nature exhibiting a complex covariance structure (van Kleunen and Ritland 2004). Estimating coefficients in univariate models may therefore reflect the indirect effects of selection acting on correlated traits. However, multivariate analysis is expected to identify the components of male fertility variation that are under direct influence of selection (Elle and Meagher 2000). Significant quadratic selection gradient coefficients indicate non-linear selection. This could indicate that there is an asymptotic relation between male fertility and the trait of interest or that there is a trait value were male fertility reaches a maximum (i.e., there is stabilizing selection) or a minimum (i.e., there is disruptive selection; Mitchell-Olds and Shaw 1987). Whenever we found significant quadratic terms, we verified whether a maximum (or minimum) is present within the distribution of trait values (Fig. 3) using a graphical approach (Mitchell-Olds and Shaw 1987).

Coefficients were initially estimated using a searching procedure similar to the one described by Smouse et al. (1999). This procedure, given the large size of the models and the data set used in this study, appeared to be faster than the Newton-Raphson method used in earlier applications of NEIGHBOR (Burczyk et al. 1996, 2002). However, we found that when traits are correlated, the sequence of the traits used in searching procedures might affect the final loglikelihood of the model. Estimating selection gradients for correlated traits presents a class of problems widely recognized (Mitchell-Olds and Shaw 1987 and references therein). Therefore, the coefficients of the models were finally estimated using the Newton-Raphson method. This method estimates coefficients based on an information matrix (i.e., the Hessian variance-covariance matrix) that takes into account the covariance of data structures, providing additionally the variances of the estimated coefficients. We determined significance levels of the coefficients with log-likelihood tests. 


\section{Results}

\section{Mating patterns}

In our study population of $M$. gutattus, estimates of self-fertilization rate were around $20 \%(\mathrm{SE}=1.9 \%)$ in the univariate models, and $26.5 \%(\mathrm{SE}=2.2 \%)$ in the multivariate model. Taking into account the paternal selection gradients and locations of males relative to mother plants, the mean effective outcross male population size for single mothers was estimated to be 12.2 in the multivariate model, which means that on average 1213 effective outcross males are fertilizing the seeds of a single seed capsule.

\section{Effects of position of plants on male mating success}

Although the average distance between sampled mother plants and potential fathers within a plot was $4.90 \mathrm{~m}$, the average dispersal distance of successful male gametes was $3.03 \mathrm{~m}$. This indicates that males are more likely to fertilize plants that are close by than the ones at larger distances. Indeed, the gradient coefficients for distance were significantly negative in the univariate and multivariate models (Table 1; Fig. 2). Moreover, offspring were most likely fathered by plants located at an angle of $330^{\circ}$ and $70^{\circ}$ from the north for the univariate and multivariate model, respectively

Table 1 Paternal selection coefficients on spatial position, and floral traits of plants (and their quadratic components) in a natural population of Mimulus guttatus

\begin{tabular}{|c|c|c|c|c|c|c|}
\hline \multirow[t]{2}{*}{ Factor } & \multicolumn{3}{|c|}{ Univariate models } & \multicolumn{3}{|c|}{ Multivariate model } \\
\hline & $\mathrm{S}$ & $\mathrm{SE}$ & $P$ & $\beta$ & SE & $P$ \\
\hline Distance & 0.318 & 0.038 & $<0.0001$ & 0.376 & 0.034 & $<0.0001$ \\
\hline Direction & 1.153 & 0.149 & $<0.0001$ & 0.447 & 0.169 & 0.0082 \\
\hline Number of open flowers & 2.024 & 0.185 & $<0.0001$ & 0.603 & 0.114 & $<0.0001$ \\
\hline (Number of open flowers) $^{2}$ & 0.442 & 0.104 & $<0.0001$ & 0.127 & 0.092 & NS \\
\hline Corolla width & 0.313 & 0.083 & 0.0002 & 0.836 & 0.419 & 0.0460 \\
\hline$(\text { Corolla width })^{2}$ & 0.403 & 0.123 & 0.0011 & 0.226 & 0.222 & NS \\
\hline Corolla length width ratio & 0.256 & 0.080 & 0.0014 & 0.645 & 0.574 & NS \\
\hline$(\text { Corolla length width ratio })^{2}$ & 3.210 & 0.715 & $<0.0001$ & 3.265 & 1.107 & 0.0032 \\
\hline Anther stigma separation & 1.381 & 0.086 & $<0.0001$ & 3.244 & 1.215 & 0.0076 \\
\hline$(\text { Anther stigma separation })^{2}$ & 0.805 & 0.256 & 0.0017 & 0.981 & 0.482 & 0.0418 \\
\hline Anther length & 0.111 & 0.111 & NS & 0.291 & 0.201 & NS \\
\hline$(\text { Anther length })^{2}$ & 0.212 & 0.061 & 0.0005 & 0.491 & 0.095 & $<0.0001$ \\
\hline Proportion of non viable pollen & 0.579 & 0.108 & $<0.0001$ & 0.580 & 0.231 & 0.0120 \\
\hline$(\text { Proportion of non viable pollen })^{2}$ & 1.053 & 0.244 & $<0.0001$ & 0.063 & 0.162 & NS \\
\hline Ovary length & 0.131 & 0.103 & NS & 0.385 & 0.342 & NS \\
\hline$(\text { Ovary length })^{2}$ & 1.498 & 0.308 & $<0.0001$ & 0.345 & 0.197 & NS \\
\hline Number of red dots & 0.201 & 0.098 & 0.0403 & 1.548 & 0.341 & $<0.0001$ \\
\hline${\text { (Number of red dots })^{2}}^{2}$ & 0.054 & 0.061 & NS & 0.022 & 0.163 & NS \\
\hline FA in number of red dots & 0.131 & 0.100 & NS & 0.944 & 0.189 & $<0.0001$ \\
\hline$(\mathrm{FA} \text { in number of red dots) })^{2}$ & 2.812 & 0.507 & $<0.0001$ & 0.973 & 0.227 & $<0.0001$ \\
\hline
\end{tabular}

Selection differentials $(S)$ of univariate models indicate total (direct and indirect) selection on each trait, and selection gradients $(\beta)$ of the multivariate model indicate direct selection on each trait. Significance of parameters was tested with log likelihood tests. In all models, we estimated besides the selection coefficients also selfing rates (see text) 




Fig. 2 Estimated effects of spatial position (distance and directionality) on male fertility in a large natural population of Mimulus guttatus

(significant direction effects in Table 1). In the multivariate model, males located north-east $\left(70^{\circ}\right)$ of mothers plants had nearly twice the probability of mating than those from opposite direction $\left(250^{\circ}\right.$; Fig 2$)$. Overall, these results indicate that plants were most likely to father offspring on plants south of them.

Paternal selection coefficients of floral traits

Univariate analyses indicated that there is significant selection for plants with fewer simultaneously open flowers which have larger but relatively less elongated corollas, a smaller anther stigma separation, a higher proportion of non-viable pollen and more red dots on the corolla (Table 1). Although these significant selection coefficients indicate directional selection, significant negative and positive selection coefficients of quadratic terms, indicate respectively stabilizing selection on corolla width, corolla length width ratio, anther stigma separation, proportion of non-viable pollen, ovary length and fluctuating asymmetry in the number of red dots on the corolla, and disruptive selection on the number of open flowers per plant and anther length (Table 1).

Multivariate analysis, which corrects for the underlying covariance structure between the measured floral traits and their quadratic terms, however, revealed partly different patterns of selection (Table 1). It showed that there is significant selection for plants with fewer open flowers which have smaller corollas, smaller anther stigma separation, a higher proportion of non-viable pollen, more red dots on the corolla and a higher fluctuating asymmetry therein (Table 1; Fig. 3). Moreover, multivariate analysis indicated stabilizing selection on corolla-width ratio, anther stigma separation and fluctuation asymmetry in the number of red dots on the corolla, and disruptive selection on anther length (Table 1; Fig. 3). 

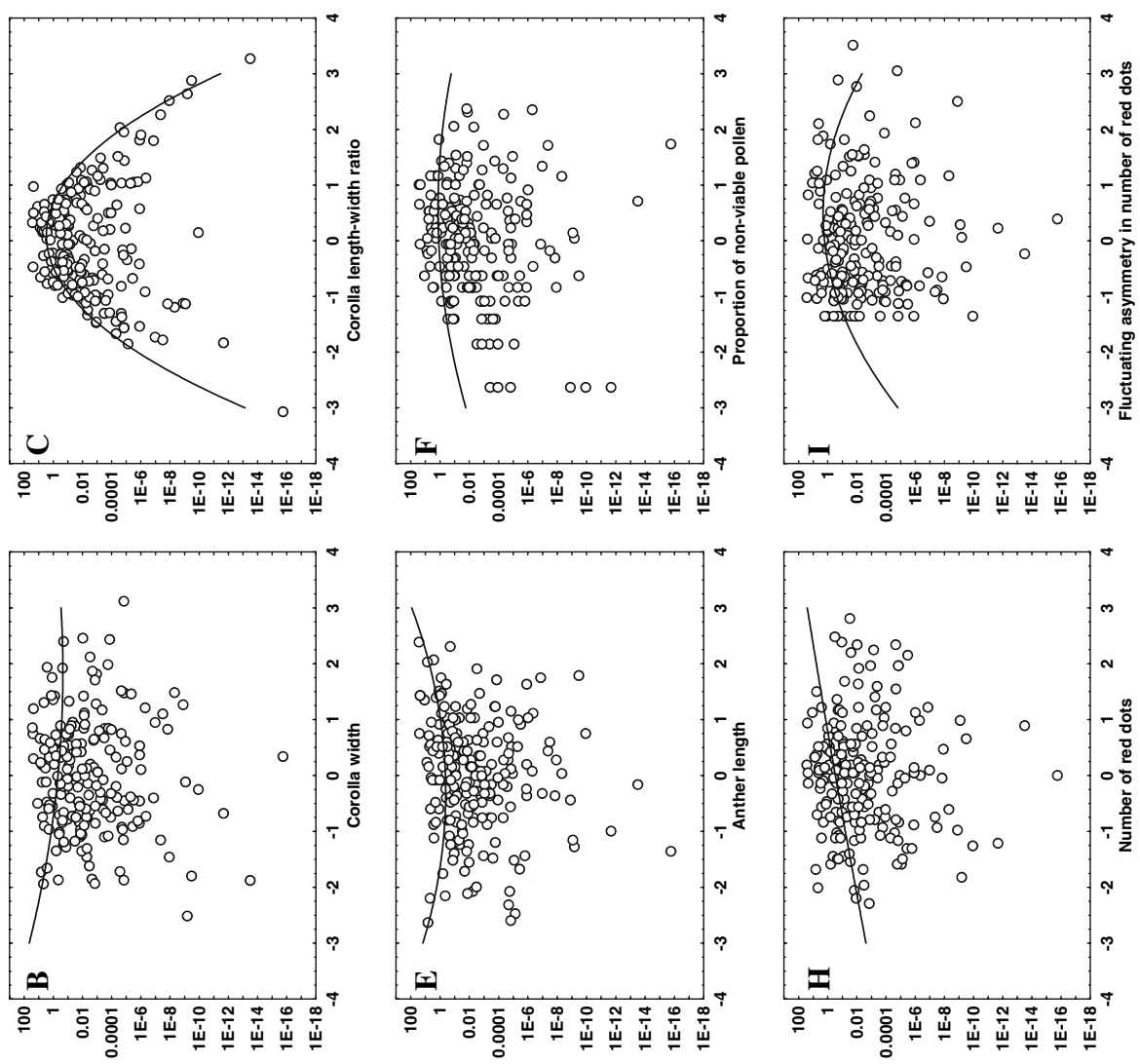

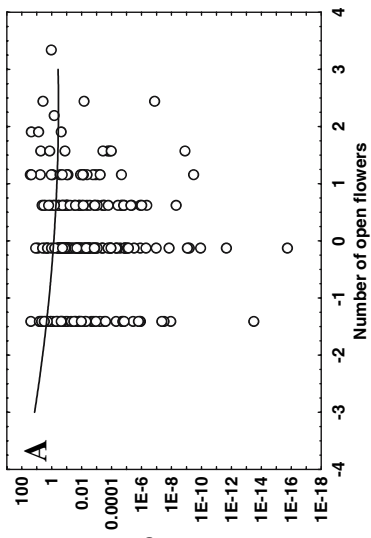

ssəoons 6u!̣eس әк!̣є|әу

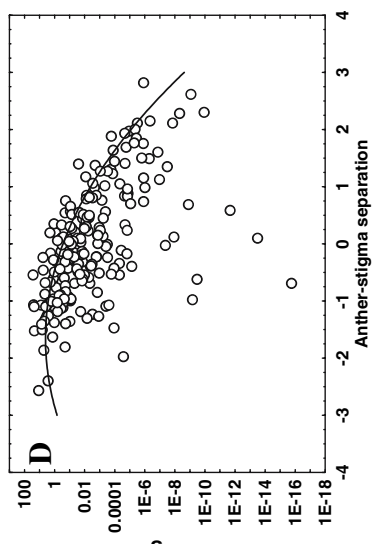

ssəoons 6u!̣еш әл!!ॄ|әу

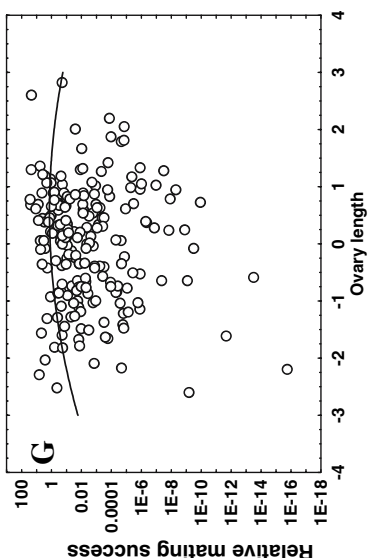

ssəoวns 6u!̣еш әм!ฺе|әу

Fig. 3 Relationships between male fertility and standardized values of (a) number of open flowers; (b) corolla width; (c) corolla length width ratio; (d) anther stigma separation; (e) anther length; (f) proportion of non viable pollen; (g) ovary length; (h) number of red dots on corolla, and (i) fluctuating asymmetry (FA) in the number of red dots on the corolla of Mimulus guttatus. Points represent estimates of male mating success under the multivariate model based on all factors assuming distance and directionality effects to be constant. Lines represent the relative paternal mating success function of the traits estimated from the multivariate model 


\section{Discussion}

Our study shows that most of the measured floral traits that are likely to be involved in pollinator attraction are under selection through paternal fitness in our study population of M. guttatus. Because the results of paternal selection gradient analysis, and therefore their biological interpretation, may strongly depend on the used methods, we will first discuss our methods followed by the biological interpretation of the results.

\section{Methodological considerations}

In previous analyses of the same data set, regression of male mating success on eight floral traits revealed only a significant negative paternal selection gradient on anther stigma separation (van Kleunen and Ritland 2004). This suggests that either selection through male fertility is of little biological importance in our study population of $M$. guttatus or that the analyses had low power to detect selection. The current analyses based on paternal probability models and maximum likelihood methods revealed many more significant paternal selection gradients in addition, indicating that the low number of significant paternal selection gradients found by van Kleunen and Ritland (2004) are mainly a consequence of the low power of the analyses. Similarly, in a reanalysis of data on floral traits of Raphanus raphanistrum that had previously been analysed with standard regression methods by Conner et al. (1996), Morgan and Conner (2001) also found more significant paternal selection gradients when they used the maximum-likelihood approach. This supports our result indicating that the maximum-likelihood approach is much more powerful than simple regression of male fertility estimates on traits of interest.

Because estimates of paternity are more accurate when all potential males in a population are sampled, other studies on paternal selection were restricted to artificial (Morgan and Conner 2001; Elle and Meagher 2000; Conner et al. 2003) or relatively small (<500 flowering plants) natural (Smouse et al. 1999; Vassiliadis et al. 2002; Wright and Meagher 2004) populations. A simulation study by Morgan and Conner (2001) showed that sampling only a fraction of the potential males in a population reduces the power to detect significant selection and underestimates the magnitude of the selection gradients. Similarly, the simulations showed that the use of markers with low exclusion probability also reduces the power to detect significant selection and underestimates selection gradients. Because we did not sample every adult individual of the population of $M$. guttatus with the marker set that has relatively low exclusion probability, the number and magnitude of significant selection coefficients are likely to underestimate true selection through paternal fertility in this population of M. guttatus.

Other studies, except for the one presented in Morgan and Conner (2001) and Conner et al. (2003), generally report no (Smouse et al. 1999; Vassiliadis et al. 2002) or only few significant paternal selection gradients (Elle and Meagher 2000; Wright and Meagher 2004), even though these studies sampled almost all potential males in the populations. The low number of significant selection gradients in these studies is most likely a consequence of their conservative way of significance testing. In principle, significance of the selection gradients can be tested by using the change in likelihood when a parameter is added to a model in log-likelihood ratio tests which 
are expected to be asymptotically chi-squared distributed (Manly 1992). However, because the latter assumption may not always hold, Smouse et al. (1999) suggested the use of non-parametric permutation tests in which the phenotype profiles are reshuffled among the males. Although in the studies using this non-parametric permutation test, selection gradients were often significant according to log-likelihood ratio tests, they were not according to the permutation test (Smouse et al. 1999; Elle and Meagher 2000; Vassiliadis et al. 2002; Wright and Meagher 2004). Morgan and Conner (2001), on the other hand, used non-parametric simulation tests in which for each simulation, individual male fertilities are calculated on basis of the estimated selection gradients to create a new offspring generation. Results of this approach agree well with the results of log-likelihood-ratio tests (Morgan and Conner 2001; Conner et al. 2003). Because in our study, single calculations of multivariate models could take up to a couple of hours, non-parametric permutations or simulations requiring at least 1,000 calculations were not feasible. However, even if we would use more conservative significance levels, most of the reported gradients would still be significant (Table 1). Moreover, the estimates of SE's of parameters, following the Newton-Raphson estimation, corresponded well with the significance tests using log-likelihood (Table 1). Therefore, we conclude that the significance levels of our paternal selection gradients are reliable.

\section{Effects of spatial position of plants on male mating success}

We found that male mating success declined with distance to the mother plants in our study population of $M$. guttatus. Similar distance effects have been found for a large number of species such as the herbs Chamaelirium luteum (Smouse et al. 1999) and Silene latifolia (Wright and Meagher 2004), the shrub Phillyrrea angustifolia (Vassiliadis et al. 2002), and the trees Pinus attenuata (Burczyk et al. 1996), Quercus sp. (Streiff et al. 1999), Eucalyptus regnans (Burczyk et al. 2002) and Picea abies (Burczyk et al. 2004). Further, Devlin and Ellstrand (1990) showed that distance may be more important than phenotypic plant characteristics in determining male fertility. Therefore, depending on how spatial position of plants is correlated with their biological traits, true selection on traits may first be apparent after correction for effects of spatial position.

In addition to a distance effect, we also found a significant effect of the direction of the plants relative to each other. Males had a higher chance of fertilizing plants south of them than plants in other directions. Such directional effects have also been found for the wind-pollinated trees Pinus sylvestris (Shen et al. 1981), P. attenuate (Burczyk et al. 1996) and Pseudotsuga menziessi (Burczyk and Prat 1997). In two of these studies (Shen et al. 1981; Burczyk and Prat 1997) the main direction of successful male gametes was downwind. In our study population of $M$. guttatus, the prevailing wind direction in the period that most of the collected seeds of $M$. guttatus have been fertilized (14 31 May 2002) was southsouth-west (188 degrees from the north, average windspeed $13.9 \mathrm{kmh}^{-1}$, data from http://www.climate.weatheroffice.ec.gc.ca/climateData/canada e.html, last visited 9 May 2006). This suggests that the pollinating insects tended to fly upwind from one flower to the next in this population of M. guttatus. Overall, these results show that the position of plants relative to others has important consequences for male fertility. 
Paternal selection coefficients of floral traits

Many of the paternal selection differentials of floral traits and their quadratic terms were significant in our study population of $M$. guttatus when we used univariate analyses. This, however, may partly be due to indirect selection on these traits as a consequence of correlations with the other traits or their quadratic terms. Indeed, when we corrected for the underlying covariance structure by including all traits and their quadratic terms simultaneously in a multivariate analysis, significance levels and even the signs of selection coefficients changed for some floral traits, indicating that selection on many of the traits is mainly indirect (Table 1). Other studies that report results of univariate and multivariate models (Elle and Meagher 2000) or different multivariate models (compare Morgan and Conner 2001 with Conner et al. 2003) also showed that the significance and signs of paternal selection coefficients depend on how many and which variables are included in the model. Like shown by many studies on maternal selection gradient analysis, this shows that it is also important to consider how many and which traits should be included in paternal selection gradient analysis.

Results of our multivariate analysis indicate that in the study population of $M$. guttatus, there is directional selection for plants with fewer simultaneously open flowers that have smaller corollas with more red dots, and a higher proportion of non-viable pollen. It has been suggested that the red dots on the corolla might direct pollinators to the two pairs of anthers in the flower (Robertson et al. 1999). Possibly a larger number of red dots on the corolla attracts more pollinators and therefore might increase male fertility.

Large flowers and a large display of open flowers on a plant are also likely to attract more pollinators and are therefore expected to increase male mating success rather than decrease it. Indeed, Martin (2004) and Ivey and Carr (2005) reported that small flowers of $M$. guttatus received fewer visits of pollinators than large flowers. Further, male mating success was increased by large floral display in Raphanus sativus (Devlin and Ellstrand 1990) and R. raphanistrum (Morgan and Conner 2001; Conner et al. 2003). However, there was no such evidence for Chamaelirium luteum (Smouse et al. 1999) and Solanum carolinense (Elle and Meagher 2000). Presumably, the discrepancy between the expectation and the result for $M$. guttatus in our study population is a consequence of the implicit assumption of paternal selection gradient models that male fertility ( $\phi_{j k}$ in Eq. 1) only applies to the fraction of outcross offspring $\left(\begin{array}{ll}1 & \mathrm{~s}\end{array}\right)$. In our study population of $M$. guttatus a larger number of open flowers per plant resulted in higher levels of self-fertilization (van Kleunen and Ritland 2004). As a consequence, in plants of $M$. guttatus with many open flowers there is relatively less pollen remaining for outcrossing (i.e., there is more pollen discounting due to selfing) and thus results in lower estimates of male fertility. This argument should also apply to corolla width which is negatively correlated with selfing rate in this population of M. guttatus (van Kleunen and Ritland 2004). Interestingly, however, our results indicate that small corolla size does not only increase male fertility through selfing but also through outcrossing. The exact reasons for this are elusive but one possibility is that some of these traits are correlated with other unmeasured traits that are under selection through male feritlity.

It also is surprising that there was selection for a higher proportion of non-viable pollen. The nutritional value of non-viable pollen is likely to be lower than that of 
viable pollen because non-viable pollen of M. guttatus are smaller (Kelly et al. 2002). The effect of pollen quality on pollinator behaviour has seldom been studied. A notable exception is a study by Robertson et al. (1999) on M. guttatus visited by bees and bumble bees in its non-native range in the United Kingdom. That study showed that bumble bees prefer patches of plants with high pollen viability but that this preference may disappear at high densities of bumble bees. Moreover, after correction for the number of viable pollen, there was a negative effect of the proportion of viable pollen (i.e., a positive effect of the proportion of non-viable pollen) on visitation rates by bees, which is in line with our results. Overall, this indicates that the proportion of non-viable pollen can affect pollinator behaviour and as a consequence male fertility.

We further found significant directional selection gradients for smaller anther stigma separation, and higher fluctuating asymmetry in the number of red dots (Table 1). However, for these traits and for the corolla-length width ratio, there was also significant stabilizing selection (Fig. 3). Evidence for stabilizing selection through paternal fitness was also found for flower size and anther exertion in Raphanus raphanistrum (Morgan and Conner 2001; Conner et al. 2003), and calyx diameter in Silene latifolia (Wright and Meagher 2004). This is in line with the general assumption that most traits have intermediate optima (e.g., Stearns and Hoekstra 2000), and thus should be under stabilizing selection. For anther length, on the other hand, we found significant disruptive selection suggesting that small and large anthers have a selective advantage over intermediate ones. Possibly, disruptive paternal selection on anther length could result from differences in anther-size preference between pollinator species.

\section{Conclusions}

In a previous study on the same population of $M$. guttatus (van Kleunen and Ritland 2004), we found significant direct selection for larger corollas and anthers through maternal fertility whereas in the current study we found selection for smaller corollas and disruptive selection on anther length through male fertility. This shows that selection on traits may differ between maternal and paternal fitness components, and therefore that both should be considered to understand adaptive evolution. Other studies, however, have often neglected selection through paternal fitness components because of methodological difficulties or restricted it to artificial or relatively small populations in which each potential male could be genotyped. This study, however, shows that even in relatively large natural populations where not all males can be sampled, it is still possible to detect significant paternal selection gradients. Such studies may give us valuable information on patterns of selection that cannot be assessed by studying female fitness only, and will therefore increase our understanding of adaptive plant evolution.

Acknowledgements We thank David Birkes from Department of Statistics, Oregon State University for discussions and suggestions on statistical aspects of ML estimation procedures and hypothesis testing, and the lab of Kermit Ritland for financing part of the allozyme work. MvK was supported by a post doctoral fellowship awarded by the Swiss National Science Foundation. 


\section{References}

Adams WT, Birkes DS (1991) Estimating mating patterns in forest tree populations. In: Fineschi S, Malvolti ME, Cannata F, Hattemer HH (eds) Biochemical markers in the population genetics of forest trees. SPB Academic Publishing, The Hague, pp 157172

Burczyk J, Prat D (1997) Male reproductive success in Pseudotsuga menziessii (Mirb.) Franco: the effects of spatial structure and flowering characteristics. Heredity 79:638 647

Burczyk J, Adams WT, Moran GF, Griffins AR (2002) Complex patterns of mating revealed in Eucalyptus regnans seed orchard using allozyme markers and the neighbourhood model. Mol Ecol 11:2379 2391

Burczyk J, Adams WT, Shimizu JY (1996) Mating patterns and pollen dispersal in a natural knobcone pine (Pinus attenuata Lemmon.) stand. Heredity 77:251 260

Burczyk J, Lewandowski A, Chalupka W (2004) Local pollen dispersal and distant gene flow in Norway spruce (Picea abies [L.] Karst.). Forest Ecol Manag 197:39 48

Broyles SB, Wyatt R (1990) Paternity analysis in a natural population of Asclepias exaltata: multiple paternity, functional gender, and the "pollen donation hypothesis". Evolution 44:1454 1468

Campbell DR (1989) Measurements of selection in a hermaphroditic plant: variation in male and female pollination success. Evolution 43:318 334

Conner JK, Rice AM, Stewart C, Morgan MT (2003) Patterns and mechanisms of selection on a family diagnostic trait: evidence from experimental manipulation and lifetime fitness selection gradients. Evolution 57:480 486

Conner JK, Rush S, Kercher S, Jennetten P (1996) Measurements of natural selection on floral traits in wild radish (Raphanus raphanistrum). II. Selection through lifetime male and total fitness. Evolution 50:1137 1146

Crow JF, Kimura M 1970. An introduction to population genetics theory. Harper and Row, New York

De Nettancourt N (1977) Incompatibility in angiosperms. Springer, New York

Devlin B, Ellstrand NC (1990) Male and female fertility variation in wild radish, a hermaphrodite. Am Nat 136:87 107

Devlin B, Roeder K, Ellstrand NC (1988) Fractional paternity assignment: theoretical development and comparison to other methods. Theor Appl Genet 76:369 380

Dudley SA (1996) Differing selection on plant physiological traits in response to environmental water availability: a test of adaptive hypotheses. Evolution 50:92 202

Elle E, Meagher TR (2000) Sex allocation and reproductive success in the andromonoecious perennial Solanum carolinense (Solanaceae). II. Paternity and functional gender. Am Nat 156:622 636

Ivey CT, Carr DE (2005) Effects of herbivory and inbreeding on the pollinators and mating system of Mimulus guttatus (Phrymaceae). Am J Bot 92:1641 1649

Kelly JK, Rasch A, Kalisz S (2002) A method to estimate pollen viability from pollen size variation. Am J Bot 89:1021 1023

Kiang YT (1972) Pollination study in a natural population of Mimulus guttatus. Evolution 26:308 310

Lande R, Arnold SJ (1983) The measurement of selection on correlated characters. Evolution 37:1210 1226

Manly BFJ (1992) The design and analysis of research studies. Cambridge University Press, Cam bridge

Marshall DL, Ellstrand NC (1988) Effective mate choice in wild radish: evidence for selective seed abortion and its mechanism. Am Nat 131:739 756

Martin NH (2004) Flower size preferences of the honeybee (Apis mellifera) foraging on Mimulus guttatus (Scrophulariaceae). Evol Ecol Res 6:777 782

Mitchell Olds T, Shaw RG (1987) Regression analysis of natural selection: statistical inference and biological interpretation. Evolution 41:1149 1161

Morgan MT, Conner JK (2001) Using genetic markers to directly estimate male selection gradients. Evolution 55:272 281

Mulcahy DL (1979) The rise of the angiosperms: a genecological factor. Science 206:20 23

O'Connell LM, Johnston MO (1998) Male and female pollination success in a deceptive orchid, a selection study. Ecology 79:1246 1260

Ritland C, Ritland K (1989) Variation of sex allocation among eight taxa of the Mimulus guttatus species complex (Scrophulariaceae). Am J Bot 76:1731 1739

Ritland K (2002) Extensions of models for the estimation of mating systems using $n$ independent loci. Heredity 88:221 228 
Robertson AW, Mountjoy C, Faulkner BE, Roberts MV, Macnair MR (1999) Bumble bee selection of Mimulus guttatus flowers: the effects of pollen quality and reward depletion. Ecology 80:2549 2606

Roeder K, Devlin B, Lindsay BG (1989) Application of maximum likelihood methods to population genetic data for the estimation of individual fertilities. Biometrics 45:363 379

Schoen DJ, Clegg MT (1985) The influence of flower color on outcrossing rate and male repro ductive success in Ipomoea purpurea. Evolution 39:1242 1249

Schoen DJ, Stewart SC (1986) Variation in male reproductive investment and male reproductive success in white spruce. Evolution 41:1109 1121

Shen H H, Rudin D, Lindgren D (1981) Study of pollination pattern in a Scots pine seed orchard by means of isozyme analysis. Silvae Genet 30:7 15

Snow AA, Lewis PO (1993) Reproductive traits and male fertility in plants: empirical approaches. Annu Rev Ecol Syst 24:331 351

Smouse PE, Meagher TR, Kobak CJ (1999) Parentage analysis in Chamaelirium luteum (L.) Gray (Liliaceae): why do some males have higher reproductive contributions?. J Evol Biol 12:1069 1077

Stanton ML, Snow AA, Handel SN (1986) Floral evolution: attractiveness to pollinators increases male fitness. Science 232:1625 1627

Stearns SC, Hoekstra RF (2000) Evolution an introduction. Oxford University Press, Oxford

Stephenson AG (1981) Flower and fruit abortion: proximate causes and ultimate functions. Annu Rev Ecol Syst 12:253 279

Streiff R, Ducousso A, Lexer C, Steinkellner H, Gloessl J, Kremer A (1999) Pollen dispersal inferred from paternity analysis in a mixed oak stand of Quercus robur L. and Q. petraea (Matt.) Liebl. Mol Ecol 8:831 841

van Kleunen M, Fischer M (2001) Adaptive evolution of plastic foraging responses in a clonal plant. Ecology 82:3309 3319

van Kleunen M, Ritland K (2004) Predicting evolution of floral traits associated with mating system in a natural plant population. J Evol Biol 17:1389 1399

Vassiliadis C, Saumitou Laprade P, Lepart J, Viard F (2002) High male reproductive success of hermaphrodites in the androdioecious Phillyrea angustifolia. Evolution 56:1962 1973

Waser NM, Price MV, Montalvo AM, Gray RN (1987) Female mate choice in a perennial herba ceous wildflower, Delphinium nelsonii. Evol Trend Plant 1:29 33

Wright JW, Meagher TR (2004) Selection on floral characters in natural Spanish populations of Silene latifolia. J Evol Biol 17:382 395

Young HJ, Stanton ML (1990) Influences of floral variation on pollen removal and seed production in wild radish. Ecology 71:536 547 